\title{
Point-of-care ultrasound to diagnose appendicitis in a Canadian emergency department
}

\author{
Sameer Sharif, MD*; Steven Skitch, MD, PhD, RDMS*; Dean Vlahaki, MBBS, RDMS*; \\ Andrew Healey, MD, RDCS, RDMS*
}

\section{ABSTRACT}

Objectives: Appendicitis is a common surgical condition that frequently requires diagnostic imaging. Abdominal computed tomography (CT) is the gold standard for diagnosing appendicitis. Ultrasound offers a radiation-free modality; however, its availability outside business hours is limited in many emergency departments (EDs). The purpose of this study is to evaluate the test characteristics of emergency physician-performed point-of-care ultrasound (POCUS) to diagnose appendicitis in a Canadian ED.

Methods: A health records review was performed on all ED patients who underwent POCUS to diagnose appendicitis from December 1, 2010 to December 4, 2015. The sensitivity, specificity, and likelihood ratios were calculated. The gold standard used for diagnosis was pathology, laparoscopy, CT scans, and a radiologist-performed ultrasound.

Results: Ninety patients were included in the study, and 24 were diagnosed with appendicitis on POCUS. Ultimately, 18 were confirmed to have appendicitis through radiologistperformed imaging, laparoscopy, and pathology. The sensitivity and specificity of POCUS to diagnose appendicitis were $69.2 \%(95 \% \mathrm{Cl}, 48.1 \%-84.9 \%)$ and $90.6 \%$ (95\% Cl, $80.0 \%-$ $96.1 \%)$, respectively.

Conclusion: POCUS has a high specificity for diagnosing acute appendicitis and has very similar characteristics to those of a radiologist-performed ultrasound. These findings are consistent with the current literature and have the potential to decrease patient morbidity, diagnostic delays, ED length of stay, and need for additional imaging.

\section{RÉSUMÉ}

Objectif: L'appendicite est une affection fréquente, qui impose une résection chirurgicale et qui exige souvent le recours à l'imagerie diagnostique. La tomodensitométrie (TDM) abdominale est l'examen de référence dans le diagnostic d'appendicite. L'échographie, elle, constitue une solution de rechange exempte de rayonnement, mais sa disponibilité en dehors des heures habituelles de travail est limitée dans de nombreux services des urgences (SU).
L'étude avait donc pour but d'évaluer les caractéristiques de l'échographie au point d'intervention (EPI), effectuée par un urgentologue, dans le diagnostic d'appendicite au SU, au Canada.

Méthode: Nous avons procédé à un examen des dossiers médicaux de tous les patients qui ont passé une EPI, au SU, en vue du diagnostic d'appendicite, du $1^{\text {er }}$ décembre 2010 au 4 décembre 2015. Ont été calculés la sensibilité, la spécificité et les rapports de vraisemblance. Les examens de référence utilisés dans le diagnostic étaient l'examen histopathologique, la laparoscopie, la TDM et l'échographie effectuée par un radiologiste.

Résultats: Au total, 90 patients ont été retenus dans l'étude et un diagnostic d'appendicite a été posé à l'aide de l'EPI chez 24 d'entre eux. Finalement, 18 cas d'appendicite ont été confirmés à l'aide de l'examen d'imagerie effectué par un radiologiste, de la laparoscopie ou de l'examen histopathologique. La sensibilité et la spécificité de l'EPI dans le diagnostic d'appendicite s'élevaient à 69,2 \% (IC à $95 \%$ : 48,1 \% - 84,9\%) et à 90,6\% (IC à $95 \%$ : 80,0 \% - 96,1\%) respectivement.

Conclusions: L'échographie au point d'intervention jouit d'une forte spécificité dans le diagnostic d'appendicite aiguë et présente des caractéristiques très comparables à celles de l'échographie effectuée par un radiologiste. Les résultats vont dans le même sens que ceux relevés dans la documentation actuelle, et l'examen offre la possibilité de réduire la morbidité, le temps écoulé avant la pose du diagnostic, la durée de séjour au SU et la nécessité de recourir à d'autres examens par imagerie.

Keywords: appendicitis, emergency department, point-ofcare ultrasound

\section{INTRODUCTION}

\section{Background}

Appendicitis is the most common cause of an acute abdomen. ${ }^{1}$ However, the diagnosis can be challenging

From the *Department of Medicine, McMaster University, Hamilton, ON

Correspondence to: Dr. Sameer Sharif, Division of Emergency Medicine, Department of Medicine, McMaster University, 237 Barton Street East, Hamilton, ON L8L 2X2; Email: sameer.sharif@medportal.ca 
because a missed appendicitis represents the third largest number of malpractice claims for emergency physicians. $^{2}$

Computed tomography (CT) scans have a sensitivity and specificity for diagnosing appendicitis of $99 \%$ and $95 \%$, respectively. ${ }^{3}$ However, an adult's approximate effective radiation dose for a CT abdomen and pelvis ranges from $11 \mathrm{mSv}$ to $20 \mathrm{mSv}$, which is comparable to a natural background radiation of 3 to 5 years. ${ }^{4}$ Although ultrasound is a radiation-free option, many emergency departments (EDs) have limited hours when it comes to ultrasound availability. Moreover, when compared to point-of-care ultrasound (POCUS), a radiologist-performed ultrasound has been shown to result in a 120-minute longer ED length of stay. ${ }^{5}$

\section{Importance}

Delays in the diagnosis of appendicitis are associated with increased morbidity and further progression of the disease process. ${ }^{6}$ Particularly, delays greater than 18 hours from ED presentation to appendectomy are associated with an increased length of stay and higher costs to the healthcare system. ${ }^{6}$

\section{Objectives}

The purpose of this study is to determine the test characteristics of POCUS use in the ED to diagnose appendicitis. The results of this study have the potential to facilitate earlier collaboration with our General Surgical colleagues in seeking definitive care for these patients resulting in decrease patient morbidity, length of stay in the ED, and the need for additional imaging.

\section{METHODS}

\section{Study design and setting}

This was a health records review of all POCUS studies for appendicitis. All studies for appendicitis and right lower quadrant pain were identified on Q-Path, the online database for POCUS scans done at an academic Canadian ED from December 1, 2011 to December 4, $2015 .^{7}$ All scans were performed by physicians with Registered Diagnostic Medical Sonographer credentials or resident physicians completing POCUS fellowship training.

\section{Study population}

All patients greater than the age of 17 years who had an ultrasound to investigate right lower quadrant pain were included in the study. All educational scans and POCUS scans completed after radiologist-performed imaging results were obtained were excluded from the study.

\section{Data collection}

A previously published framework for completing medical record review studies was followed. ${ }^{8}$ Abstractors were emergency medicine residents who were trained by abstracting data from practice medical records and were blinded to the hypothesis. The results were compared to a gold standard of pathology, if available. If pathology was not available, the gold standard was considered to be laparoscopy, CT scans, and radiologist-performed ultrasounds, respectively. The gold-standard results were abstracted independently of the POCUS results.

For the purposes of this study, POCUS was considered positive if the appendix was visualized, non-compressible with an external diameter of more than $6 \mathrm{~mm}$. Indeterminate scans or scans where the appendix was not visualized were considered to be negative in accordance with literature showing high negative predictive values of non-diagnostic and indeterminate ultrasound imaging for appendicitis. ${ }^{9}$ However, patients who were POCUSindeterminate with a high suspicion of appendicitis were imaged by Radiology.

\section{Outcome measures and analysis}

The primary outcome was the rate of correctly diagnosed appendicitis through POCUS. The specificity, sensitivity, and likelihood ratios of POCUS to diagnose appendicitis were calculated. The $95 \%$ confidence intervals (CI) were also calculated using the Wilson score.

\section{Ethical issues}

This study was subject to an ethics review and was approved by the Hamilton Integrated Research Ethics Board prior to a data abstraction commencement.

\section{RESULTS}

There were 94 patients included in the study. Four were excluded because 3 of the patients had educational ultrasounds performed on them, and 1 did not have the 


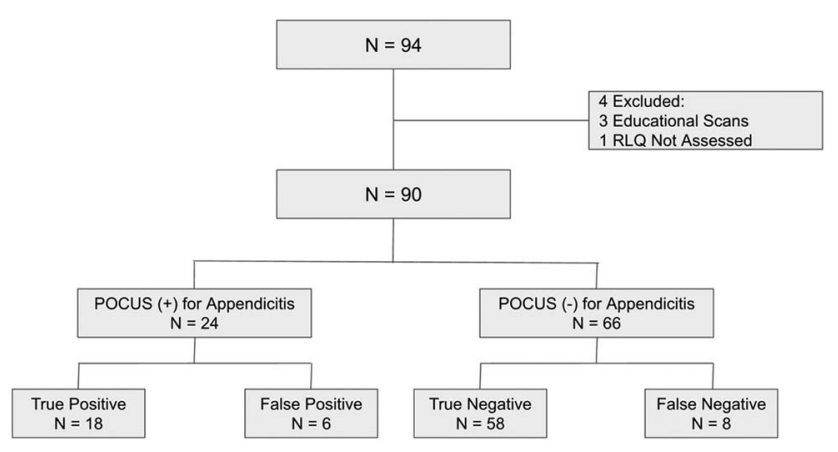

Figure 1. Study flowchart. POCUS = point-of-care ultrasound; $\mathrm{N}=$ number; $\mathrm{RLQ}=$ Right-Lower-Quadrant.

right lower quadrant assessed (Figure 1). Twenty-four patients had positive POCUS findings for appendicitis, and 66 patients had a negative and/or indeterminate findings for appendicitis (see Supplementary Table 1). There were 6 patients with false-positives in this study (see Supplementary Table 2) and 8 patients with falsenegatives (see Supplementary Table 3).

\section{Primary results}

The sensitivity and specificity for POCUS to diagnose appendicitis was found to be $69.2 \%$ (95\% CI, $48.1 \%$ $84.9 \%$ ) and $90.6 \%$ (95\% CI, 80.0\%-96.1\%), respectively (see Supplementary Table 4). In addition, Cohen's kappa statistic was determined to be 1.0. The positive likelihood ratio for POCUS to diagnose appendicitis was found to be 7.4 (95\% CI, 3.3-16.5), and the negative likelihood ratio was found to be 0.3 (95\% CI, 0.2-0.6).

\section{DISCUSSION}

These results are comparable to current literature on POCUS for appendicitis, as shown in a study by Mallin et al. in 2015. This prospective study of 97 adult cases yielded a sensitivity of $67.65 \%$ (95\% CI, $49.5 \%-82.6 \%$ ) and a specificity of $98.41 \%$ (95\% CI, $91.4 \%-99.7 \%$ ) of diagnosing appendicitis with bedside ultrasound. ${ }^{10}$ If all patients who were POCUS-positive for appendicitis went to the operating room directly, it would result in a $26.7 \%$ reduction in diagnostic imaging utilization.

This study's strengths include a robust review of the medical records with trained abstractors using specific data abstraction forms. Of critical importance, the Cohen's kappa statistic was found to be 1.0, and all scans were subject to a rigorous quality-assurance process.

\section{LIMITATIONS}

One of the limitations of this study is the lack of consecutive patient enrolment because not all patients suspected of appendicitis had an ultrasound performed by emergency physicians (i.e., patients with low pretest probability may not have had POCUS). This limited our data set and could have potentially confounded our results through selection bias. Moreover, this study is also limited because of the small number of patients included leading to wide CIs. This contributed to the positive and negative likelihood ratios to not reach significant values. However, using a pretest probability in combination with POCUS findings and other tests will still be of benefit. Further steps that could be taken to improve this study would be to perform a prospective study with a larger patient population.

\section{CONCLUSIONS}

POCUS is a reliable imaging modality for ruling in acute appendicitis. In cases where POCUS is negative or indeterminate for appendicitis, further imaging should be obtained as clinical suspicion warrants. Given the high specificity and positive likelihood ratio, the use of POCUS with a high pretest probability can hasten the process of achieving definitive management through earlier surgical consultation. This has the potential to decrease patient morbidity, length of stay in the ED, and the need for additional imaging.

Acknowledgements: The authors thank McMaster University and St. Joseph's Healthcare Hamilton for their work in this study.

Competing interests: This research received no specific grant from any funding agency, commercial or not-for-profit sectors. The authors have no disclosures to make.

\section{SUPPLEMENTARY MATERIALS}

To view Supplementary Material for this article, please visit https://doi.org/10.1017/cem.2018.373

\section{REFERENCES}

1. Davies G, Dasbach EH, Teutsch S. The burden of appendicitis related hospitalizations in the United States in 1997. Surg Infect 2004;5(2):160-5.

2. Brown TW, McCarthy ML, Kelen GD, et al. An epidemiologic study of closed emergency department malpractice 
claims in a national database of physician malpractice insurers. Acad Emerg Med 2010;17:553-60.

3. Eko FN, Ryb GE, Drager L, et al. Ideal timing of surgery for acute uncomplicated appendicitis. $N \mathrm{Am} f \mathrm{Med}$ Sci 2013;5(1):22-7, doi:10.4103/1947-2714.106186.

4. Wilson SP, Connolly K, Lahham S, et al. Point-of-care ultrasound versus radiology department pelvic ultrasound on emergency department length of stay. World 7 Emerg Med 2016;7(3):178-82, doi:10.5847/wjem.j.1920-8642.2016.03.003.

5. Rhea J, Halpern EF, Ptak T, et al. The status of appendiceal CT in an urban medical center 5 years after its introduction: experience with 753 patients. Am 7 Roentgenol 2005;184(6): 1802-8.

6. Smith-Bindman R, Lipson J, Marcus R, et al. Radiation dose associated with common computed tomography examinations and the associated lifetime attributable risk of cancer. Arch Intern Med 2009;169(22):2078-86.

7. Mallin M, Craven P, Ockerse P, et al. Diagnosis of appendicitis by bedside ultrasound in the ED. Am 7 Emerg Med 2015;33:430-2.

8. Telexy Healthcare. Q-PATH; 2013. Available at: http:// www.telexy.com/our-products/qpath/.

9. Worster A, Haines T. Advanced statistics: understanding Medical Record Review (MRR) studies. Acad Emerg Med 2004;11(2):187-92, doi:10.1111/j.1553-2712.2004.tb01433.x.

10. Cohen B, Bowling J, Midulla $\mathrm{P}$, et al. The non-diagnostic ultrasound in appendicitis: is a non-visualized appendix the same as a negative study? $\mathcal{F}$ Pediatr Surg 2015;50(6):923-7, doi:10.1016/i.jpedsurg.2015.03.012. 